\title{
Spatial and temporal distribution of mineral nutrients and sugars throughout the lifespan of Hibiscus rosa-sinensis L. flower
}

Research Article

Alice Trivellini ${ }^{1}$, Antonio Ferrante ${ }^{2, \star}$, Paolo Vernieri ${ }^{1}$, Giulia Carmassi ${ }^{1}$, Giovanni Serra ${ }^{3}$

'Department of Crop Biology, Università degli Studi di Pisa,

56124 Pisa, Italy

${ }^{2}$ Department of Plant Production, Università degli Studi di Milano,

20133 Milano, Italy

${ }^{3}$ Sant'Anna School of Advanced Studies,

56127 Pisa, Italy

Received 22 October 2010; Accepted 28 February 2011

Abstract: Although the physiological and molecular mechanisms of flower development and senescence have been extensively investigated, a whole-flower partitioning study of mineral concentrations has not been carried out. In this work, the distribution of sucrose, total reducing sugars, dry and fresh weight and macro and micronutrients were analysed in Hibiscus rosa-sinensis L. petals, stylestigma including stamens and ovary at different developmental stages (bud, open and senescent flowers). Total reducing sugars showed the highest value in petals of bud flowers, then fell during the later stages of flower development whereas sucrose showed the highest value in petals of senescent flowers. In petals, nitrogen and phosphorus content increased during flower opening, then nitrogen level decreased in senescent flowers. The calcium, phosphorus and boron concentrations were highest in ovary tissues whatever the developmental stage. Overall, the data presented suggests that the high level of total reducing sugars prior the onset of flower opening contributes to support petal cells expansion, while the high amount of sucrose at the time of petal wilting may be viewed as a result of senescence. Furthermore, this study discusses how the accumulation of particular mineral nutrients can be considered in a tissue specific manner for the activation of processes directly connected with reproduction.

Keywords: Flower parts $\bullet$ Reducing sugars $\bullet$ Sucrose $\bullet$ Micronutrients $\bullet$ Macronutrients $\bullet$ Flower senescence $\bullet$ Remobilization $\bullet$ Osmoregulation (C) Versita Sp. z 0.0 .

\section{Introduction}

Flower senescence is an irreversible process which goes through precise developmental control, thus, providing an excellent model system for senescence studies. The complex nature of flower senescence process involves different flower tissues, which are coordinated by inter-organ signals. Senescence occurs in floral tissues at different stages of development and it can be characterized by distinct morphological changes and triggered by endogenous signals [1]. The Hibiscus rosa-sinensis flowers (cv La France) senesce and die over a 12 hours period after opening and they are considered an ephemeral flower. Hibiscus flowers are very sensitive to ethylene, which shortens the duration and compromises the quality of the flowers
[2]. Early studies on the biosynthesis of ethylene in the flower were carried out by Woodson et al. [3] who demonstrated the role of the hormone during senescence. Furthermore, the longevity of hibiscus flowers has been shown to be negatively correlated with both ethylene and ABA levels in petals [4]. Few studies have focused on the role of sugars and changes in mineral nutrient concentrations pertaining to their spatial distribution within floral tissues during flower development and senescence. The high level of hexose sugar prior to the onset of flower opening contributes to supporting water influx by reducing the petal water potential [5]. Acid invertase activity is tightly connected with the metabolism of sucrose to hexoses, from source organs, such as leaves to the sink organs such as petals [6], potato tubers [7] and carrot roots

\footnotetext{
*E-mail: antonio.ferrante@unimi.it
} 
[8]. Invertase activities significantly increased during flower opening and thus seem to be associated with the petal growth [9].

Carbohydrates, in particular sucrose and glucose, play a crucial role in plant metabolism, beside being an energy source they can have osmoregulatory functions and act as signalling molecules involved in crucial processes the life of the plant [10]. When senescence symptoms are obviously visible the sugar pool is still adequately detectable, which is in contrast to the positive effect that exogenous sugars exert on the time to senescence in cut flowers $[11,12]$. In fact, the gradual decline in respiration during aging in flowers, which leads to flower senescence, has been associated with a short supply of readily respirable substrates, mainly sugars. The presence of considerable amounts of sugars in petals of senescent flowers may be an effect of mobilization, as van Doorn suggested [12], but so far, detailed measurements of sugar pools in different floral parts and developmental stages has not been fully investigated. Flower senescence is an active process that provides the degradation of macromolecules and cell membranes, allowing the remobilization and recycling of important nutrients to other plant organs. In Petunia changes in the mineral nutrient concentrations during development and senescence of corolla have been reported [13]. The remobilization of nitrogen, phosphorus and potassium occurs during petal senescence with a significant reduction in levels over time. No significant changes were observed in the level of sulphur, calcium, magnesium and micronutrients of the corollas during development. In leaf senescence, it has been shown by Himelblau and Amasino [14] that in addition to most essential macronutrients, such as carbon, nitrogen and phosphorus, the levels of chromium, iron, copper, molybdenum, zinc and sulphur levels also decrease. Relatively little is known about changes in macro and micronutrient concentrations in different floral organs during flower development and senescence.

The use of ephemeral flowers of Hibiscus offers a good model for studying the developmental process of senescence. For this species, the senescence was previously described by Woodson et al. [3] as rapid and reproducible, and it was characterized by an in-rolling of corolla followed by corolla wilting and abscission. Moreover, the flowers are large and well shaped and the different flower parts can be easily separated. In the present work, to gain better understanding of hibiscus ephemeral flower development, attention was paid on the spatial distribution of reducing sugars, macro- and micronutrient in different floral tissues during three well characterized flower developmental stages.

\section{Experimental Procedures}

\subsection{Plant materials and growth conditions}

Hibiscus rosa-sinensis L. plants, cv. 'La France', were used in all experiments. The plants were grown in a greenhouse under natural environmental conditions. Flowers cut from the plants were used as experimental material and were harvested at bud stage, $24 \mathrm{~h}$ before full bloom, fully opened flowers and petal in-rolling senescent flowers. All experiments were performed between May 15 and September 30 (2009, Pisa, Italy). Flowers were harvested between 7:30 and 8:00 a.m. either on the morning of flower opening (opened flowers, OF) or on the morning of the day before opening (bud flowers, B) or on the morning of the day after opening (senescent flowers, SF). The stages of flower development used in this study are showed in Figure 1. The cut flowers were immediately transported to the laboratory for the subsequent analysis.

\subsection{Macronutrients and micronutrients determination}

The petal, style-stigma plus stamen (s-s+s) and ovaries were isolated from the harvested flowers. Each flower tissue was grouped in three independent biological replicates of 20 flowers, dried for 3 days in a $70^{\circ} \mathrm{C}$ oven, ground in a mortar with pestle to pass a 40-mesh screen, and stored at $-20^{\circ} \mathrm{C}$ for later analysis. Fresh weight (FW) was taken immediately before drying. Dry weight (DW) was measured after the tissues were ground to a powder. The oven-dried-ground samples were wet digested in a mixture of nitric-perchloric acids $\left(\mathrm{HNO}_{3}: \mathrm{HClO}_{4}, 5: 2 \mathrm{v} / \mathrm{v}\right)$. Potassium, calcium, magnesium, iron, manganese and zinc concentrations in the wet digested samples were quantified by atomic absorption spectrophotometry (Varian Model SpectraAA240 FS, Australia). Boron was determined by the Azomethine- $\mathrm{H}$ method [15]. Nitrogen was determined by the micro-Kjeldahl procedure [16], and phosphorus was measured by spectrophotometry using the molybdenum blue method [17].

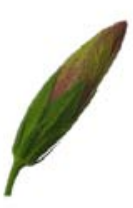

B

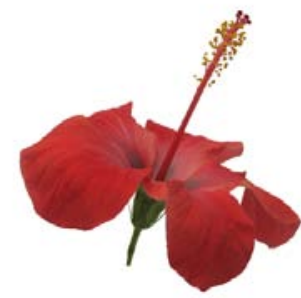

OF

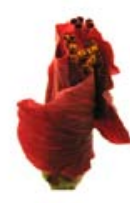

SF
Figure 1. H. rosa-sinensis flower developmental stages. B, Bud stage; OF, opened flower stage; SF, senescent flower stage. 
Nitrate content was measured by spectrophotometry using the salicylic-sulphuric acid method. For each sample $100 \mathrm{mg}$ of DW were ground and placed in $30 \mathrm{~mL}$ icon glass with $10 \mathrm{~mL}$ of distilled water. Samples were placed on the shaking machine for $2 \mathrm{~h}$ at room temperature. After shaking $10 \mathrm{~mL}$ of each sample was centrifuged at $4000 \mathrm{rpm}$ for $15 \mathrm{~min}$. The supernatant was recovered and $200 \mu \mathrm{l}$ was added to $800 \mu \mathrm{l}$ of $5 \%$ salicylic acid in sulphonic acid. The icon glass was placed on the stirring machine and $30 \mathrm{~mL} \mathrm{NaOH} 1.5 \mathrm{~N}$ was slowly added. Samples were then cooled to room temperature and spectrophotometer readings were performed at $410 \mathrm{~nm}$ [18]. The nitrate content was calculated using calibration standards containing $0,1,2.5,5,7.5$ and $10 \mathrm{mM} \mathrm{KNO}_{3}$.

\subsection{Carbon cost of flowering}

The carbon cost of flowering in the different floral tissues, was determined by measuring the fresh and dry weight of flowers [19] at the three developmental stages, B, OF and SF.

\subsection{Sucrose and reducing sugars determinations}

The petal, s-s+s and ovaries were isolated from the harvested flowers. For the determination of sucrose, $2 \mathrm{~g}$ of tissue was extracted by homogenization in a mortar with water or $0.1 \%$ TCA solution. The insoluble material was separated by centrifugation at $10000 \times \mathrm{g}$ for $5 \mathrm{~min}$. The sucrose assay was performed by mixing $0.2 \mathrm{~mL}$ of crude extract with $0.2 \mathrm{~mL} \mathrm{NaOH} 2 \mathrm{~N}$ and incubated in a water bath at $100^{\circ} \mathrm{C}$ for $10 \mathrm{~min}$, then $1.5 \mathrm{~mL}$ hot resorcinol buffer was added to samples and incubated in a water bath at $80^{\circ} \mathrm{C}$ for other $10 \mathrm{~min}$. Resorcinol solution was prepared by mixing $250 \mathrm{~mL} \mathrm{HCl} \mathrm{30 \% ,35} \mathrm{mg} \mathrm{resorcinol}$ (Sigma, Italy), $90 \mathrm{mg}$ thiourea (Sigma, Italy), $25 \mathrm{~mL}$ acetic acid and $10 \mathrm{~mL}$ distilled water. After cooling at room temperature, the optical density was determined spectrophotometrically at $500 \mathrm{~nm}$, using a sucrose standard curve $(0,0.5,1,1.5$ and $2 \mathrm{mM})$. The reducing sugars analysis was performed using $0.2 \mathrm{~mL}$ of crude extract that were added to $0.2 \mathrm{~mL}$ of dinitrosalicylic acid (DNS) the reaction mixture was heated at $100^{\circ} \mathrm{C}$ for $5 \mathrm{~min}$, then $1.5 \mathrm{~mL}$ of distilled water was added and absorbance readings were taken at $530 \mathrm{~nm}$. The reducing sugars were expressed as glucose equivalent using a glucose standard curve $(0,1,2,3$ and $4 \mathrm{mM})$.

\subsection{Osmolytes measurements}

Frozen flower tissues were freeze/thawed, and the sap was expressed, centrifuged at $5000 \times \mathrm{g}$ and its osmolarity was determined using an automatic freezingpoint depression osmometer (Digital Osmometer, Roebling, Berlin, Germany) calibrated with sodium chloride solutions.

\subsection{Statistical Analysis}

For each experiment the means of three independent biological samples were calculated. Statistical differences among mean values $(P<0.05)$ were determined by two-way ANOVA followed by Bonferroni's test to compare the reducing sugars content, sucrose, macro and micronutrients distribution among different floral tissues. The statistical analyses were carried out using GraphPad Prism 5 for Windows v8.0 (GraphPad Software, San Diego, CA, USA).

\section{Results}

\subsection{Dry and fresh weight}

The fresh and dry mean weight for petals, stylestigma plus stamens (s-s+s), and ovary tissues for three developmental stages are shown in Table 1. During the flower opening an increase in fresh weight was observed. Then, in senescent flowers, the fresh weight decreased in both, petals and $\mathrm{s}-\mathrm{s}+\mathrm{s}$ tissues. Similar trend was observed for the dry matter content; it increased almost twice from buds to opened flowers stage, and dropped off again during senescence. On the contrary, the ovaries showed a progressive increase in fresh weight, peaking at senescent flower stage. The dry weight of the ovaries also showed an increase between

\begin{tabular}{|c|c|c|c|c|c|c|c|c|c|}
\hline & \multicolumn{3}{|c|}{ Petals } & \multicolumn{3}{|c|}{ Style-Stigma + stamens } & \multicolumn{3}{|c|}{ Ovaries } \\
\hline DS & B & OF & SF & $B$ & OF & SF & $\mathrm{B}$ & OF & SF \\
\hline FW & $2.15 \pm 0.05$ & $2.78 \pm 0.065$ & $2.38 \pm 0.085$ & $0.58 \pm 0.070$ & $1.16 \pm 0.024$ & $0.85 \pm 0.048$ & $0.10 \pm 0.006$ & $0.12 \pm 0.004$ & $0.17 \pm 0.04$ \\
\hline DW & $0.14 \pm 0.041$ & $0.26 \pm 0.011$ & $0.19 \pm 0.004$ & $0.07 \pm 0.007$ & $0.13 \pm 0.005$ & $0.08 \pm 0.014$ & $0.01 \pm 0.003$ & $0.02 \pm 0.005$ & $0.02 \pm 0.005$ \\
\hline
\end{tabular}

Table 1. Fresh and dry weight of flowers (g) in different floral tissues from three different developmental stages. Three developmental stages (DS): B, buds; OF, opened flowers; SF, senescent flowers. FW, fresh weight; DW, dry weight. Each data represents the mean of 10 flowers \pm standard error (SE). 
bud and opened flower stage, but in senescent flowers it remained constant.

\subsection{Changes in macro and micronutrients during hibiscus flower development and senescence}

The phosphorous $(P)$ content was different in the different flower organs. The lowest value was found in the ovary and the highest in the petal. In petals and $\mathrm{s}-\mathrm{s}+\mathrm{s}$, the $\mathrm{P}$ content increased in open flowers and decreased in senescent flowers reaching the same level as in buds (Figure 2A). No differences in $\mathrm{P}$ concentration among the three stages were observed in the ovary, with an average value of about $0.1 \mathrm{mg}$ per organ. Potassium $(\mathrm{K})$ content showed similar trend to $\mathrm{P}$ even if the concentrations were 7-8 fold higher. The $\mathrm{K}$ content increased in open flowers and decreased in senescent flowers (Figure 2B), in both petals and $s-s+s$ tissues. The petals had the highest content (6 mg per organ at the open flower stage) and the ovaries the lowest (in average $0.12 \mathrm{mg}$ per organ; Figure $2 \mathrm{~B}$ ). The $\mathrm{s}-\mathrm{s}+\mathrm{s}$ tissues again had intermediate $\mathrm{K}$ concentrations compared to other flower organs, ranging from 1.4 to $2.4 \mathrm{mg}$ per organ. The calcium ( $\mathrm{Ca}$ ) content did not significantly change among the different flower developmental stages within the same tissue. In s-s-+s and in ovary tissues we found the same Ca concentrations, ranging from 0.14 to $0.25 \mathrm{mg}$ per organ. In petals the $\mathrm{Ca}$ concentration was 1 fold higher than other tissues, $0.4 \mathrm{mg}$ per organ in average (Figure $2 \mathrm{C}$ ). Moreover, Ca was the most abundant mineral nutrient present in the ovary. In both petals and s-s+s tissues, as observed for $\mathrm{P}$ and $\mathrm{K}$, the magnesium (Mg) content increased in open flowers and decreased in senescent ones flowers reaching the same level as in buds (Figure 2D). The highest concentration of $\mathrm{Mg}$ was found in petals at the fully open flower stage $(0.48 \mathrm{mg}$ per organ in average), followed by the $s-s+s$ tissues (0.35 mg per organ). The Mg content did not change in ovary tissues at the different flower developmental stages. In this tissue the concentration was about $0.06 \mathrm{mg}$ per organ (Figure 2D). The iron (Fe) content
A
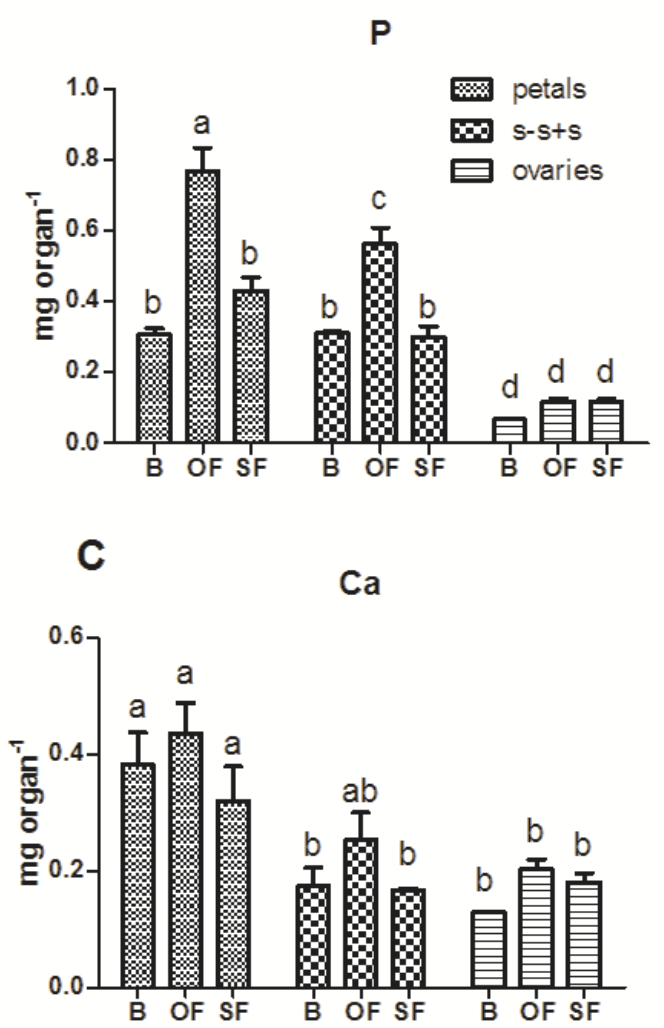

B

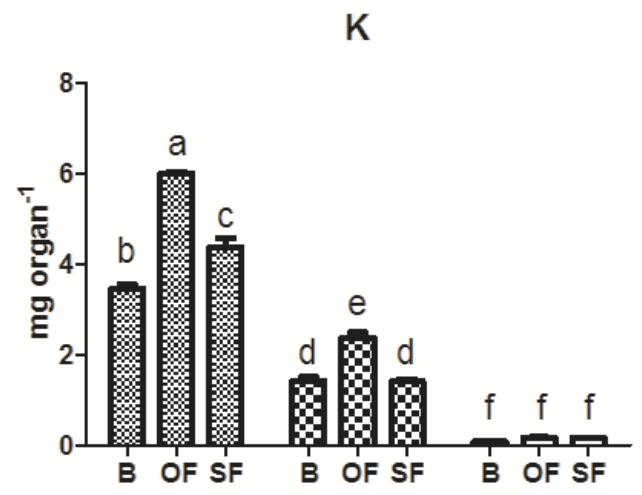

$\mathrm{Mg}$

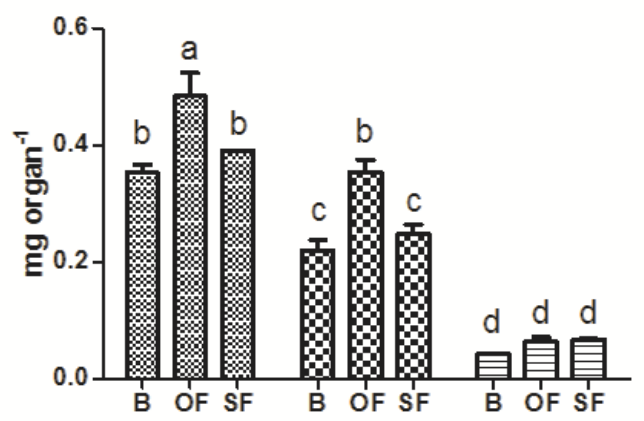

Figure 2. Macronutrient concentration in three floral tissues of $H$. rosa-sinensis. The contents of phosphorus (P), potassium (K), calcium (Ca) and mangnesium (Mg) were measured at bud (B), opened flower (OF) and senescent flower stage (SF). Data were subjected to two way analysis of variance. Different letters above each data point indicate significant differences (Bonferroni's test, $\mathrm{P}<0.05)$. Mean values $(n=3) \pm$ standard error (SE). Each biological independent replicate included 20 flowers. 
increased in petals of open flowers and then remained almost constant during the senescence stage. The $\mathrm{Fe}$ was the most abundant micronutrient in petal tissue, with values ranging from 8 to $16 \mu \mathrm{g}$ per organ. The $\mathrm{Fe}$ concentration in $\mathrm{s}-\mathrm{s}+\mathrm{s}$ and ovary tissues was similar without differences among developmental stages. As observed for $\mathrm{Fe}$, the manganese $(\mathrm{Mn})$ content increased in petals of open flowers and maintained the same levels during the senescence stage. In s-s+s the $\mathrm{Mn}$ concentration increased between the bud and open flower stage, and decreased in senescent flowers reaching the same levels found in buds (Figure 3B). The ovary did not show any significant change in Mn content during development and senescence. The zinc ( $\mathrm{Zn})$ content in petals and s-s+s tissues increased during flower opening and then decreased in senescent flowers (Figure $3 \mathrm{C}$ ), whereas in the ovary the $\mathrm{Zn}$ concentration did not change. As observed for $\mathrm{P}, \mathrm{K}, \mathrm{Mg}, \mathrm{Fe}, \mathrm{Mn}$ and $\mathrm{Zn}$, the boron $(\mathrm{B})$ levels in petals increased in open flowers compared to buds. The $B$ concentration also increased in the s-s+s tissues during flower opening and remained constant during senescence. Moreover, the B was the most abundant micronutrient in both s-s+s and ovary tissues, with values ranging from 4 to 9 and 1 to $2 \mu \mathrm{g}$ per organ respectively (Figure 3D).

The total $\mathrm{N}$ content in petals strongly increased during flower opening, more than 10-fold compared to buds, then sharply decreased in senescent flowers (Figure 4A). In s-s+s tissues, the total $\mathrm{N}$ content increased in open flowers and decreased in senescent flowers reaching the same level found buds. In the ovary, the total $\mathrm{N}$ content did not change among the different flower developmental stages. The organic $\mathrm{N}$ concentration among development stages showed the same trend as the total $N$ (Figure 4B). In petals it increased during flower opening compared to buds, then decreased in senescent flowers. In s-s+s tissues, the organic $\mathrm{N}$ increased in open flowers and decreased in senescent flowers, reaching the same level as in buds. In the ovary, the organic $\mathrm{N}$ content did not change among the different flower developmental stages. Also the nitrate content (Figure 4C) showed the same trend
A

$\mathrm{Fe}$

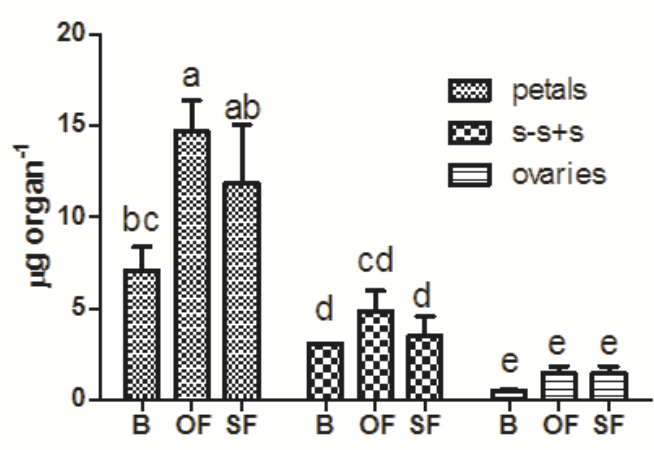

C

$\mathrm{Zn}$

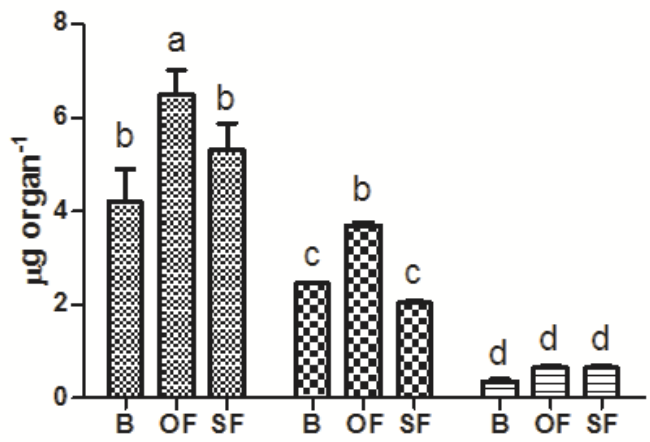

B

Mn

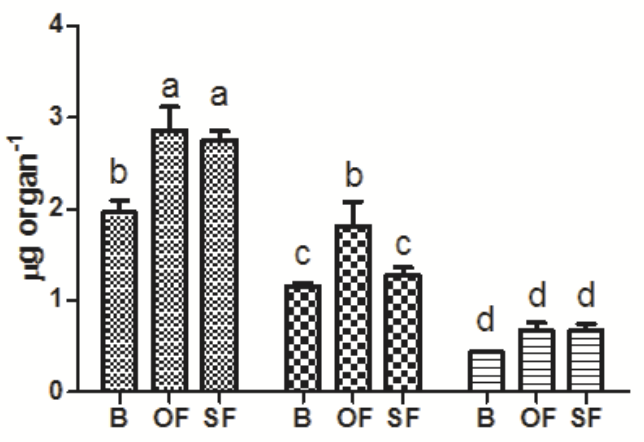

D

B

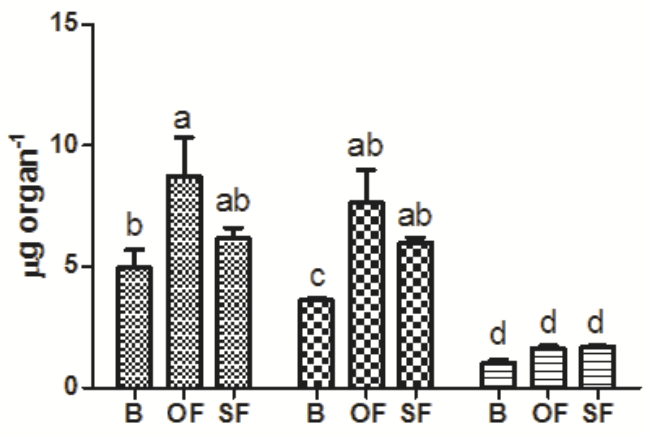

Figure 3. Micronutrient concentration in three floral tissues of $H$. rosa-sinensis. The contents of iron (Fe), manganese (Mn), zinc ( $\mathrm{Zn})$ and boron (B) were measured at bud (B), opened flower (OF) and senescent flower stage (SF). Data were subjected to two way analysis of variance. Different letters above each data point indicate significant differences (Bonferroni's test, $P<0.05)$. Mean values $(n=3) \pm$ standard error (SE). Each biological independent replicate is constituted of 20 flowers. 
A

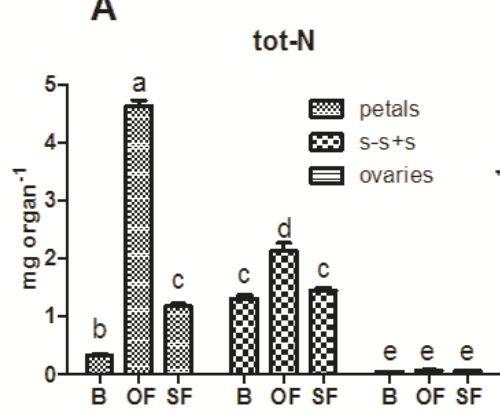

B

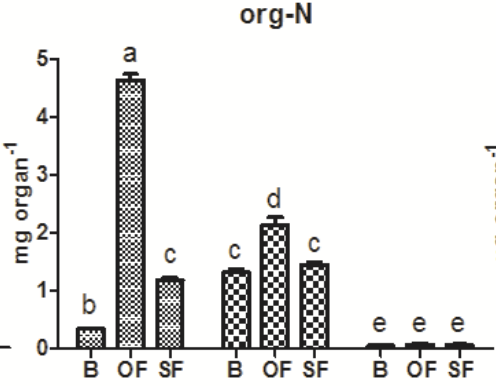

C

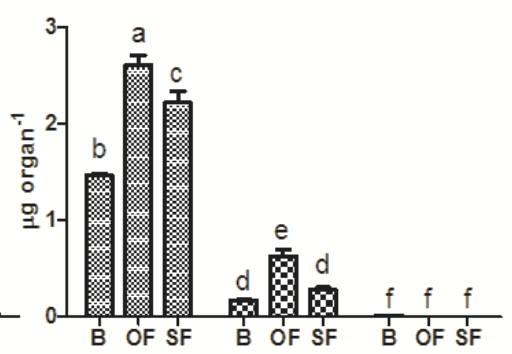

Figure 4. Total nitrogen, organic nitrogen and nitrate concentrations in three floral tissues of $H$. rosa-sinensis. The total nitrogen (tot- $\mathrm{N}$ ), organic nitrogen (org-N) and nitrate (N-NO), were measured at bud (B), opened flower (OF) and senescent flower stage (SF). Data were subjected to two way analysis of variance. Different letters above each data point indicate significant differences (Bonferroni's test, $\mathrm{P}<0.05)$. Mean values $(n=3) \pm$ standard error (SE). Each biological independent replicate is constituted of 20 flowers.

as previously observed for both total and organic N. The nitrate content showed the highest value in petals of open flowers, reaching $2.6 \mu \mathrm{g}$ per organ. In s-s+s tissue the nitrate concentration also increased in open flowers but was about 3-fold lower than those observed in petals. In the ovary the nitrate content did not change in the different flower stages and showed the lowest values.

\subsection{Reducing sugars levels during flowers development and senescence}

Reducing sugars and sucrose contents were determined in petals, $s-s+s$ and ovaries at each developmental stage. The highest level of reducing sugars, expressed as glucose equivalent (mg per organ), was found in petals of buds with values that overcome $500 \mathrm{mg}$ per organ. Then the reducing sugar content declined to $250 \mathrm{mg}$ per organ in petals of the opening and senescing flowers (Figure 5A). The $\mathrm{s}-\mathrm{s}+\mathrm{s}$ and ovary tissues showed very low concentrations of reducing sugars, exhibiting a 5 to 10 -fold reduction, without significant differences among the various developmental stages. In contrast, sucrose level in petals doubled in senescent flowers compared to buds or open flowers (Figure 5B). No changes in sucrose levels in $\mathrm{s}-\mathrm{s}+\mathrm{s}$ tissues and ovaries were observed among the different developmental stages and the values were significantly lower compared to those observed in petals.

\subsection{Osmolytes concentration}

Total osmotic compounds doubled in petals between bud and open flower stages. The highest value was found in open flowers (10.5 Osmol kg-1 $\mathrm{H}_{2} \mathrm{O}$ per organ) and then in senescent flowers, where a slight decrease
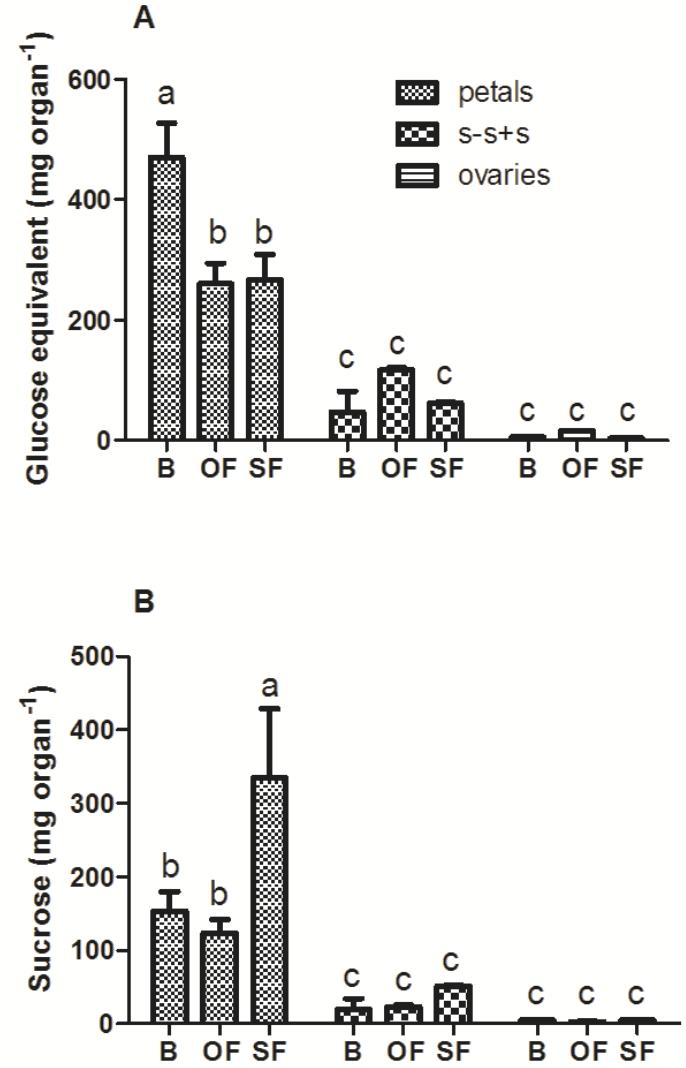

Figure 5. Sucrose and reducing sugars levels in three floral tissues of $H$. rosa-sinensis among three developmental stages were measured at bud (B), opened flower (OF) and senescent flower stage (SF). Data were subjected to two way analysis of variance. Different letters above each data point indicate significant differences (Bonferroni's test, $P<0.05)$. Mean values $(n=3) \pm$ standard error (SE). 
was observed (8.7 Osmol kg-1 $\mathrm{H}_{2} \mathrm{O}$ per organ, Figure 6). In s-s+s tissues the osmolytes content increased during flower opening then returned to the same values found at bud stage. The ovary showed the lowest values of osmolytes and did not significantly change among the developmental stages (Figure 6).

\section{Discussion}

\subsection{Role of sugars in flower senescence}

The flower development in $H$. rosa-sinensis was found to be dependent on carbohydrate metabolism. The high level of reducing sugars prior the onset of flower opening in $H$. rosa-sinensis is likely to induce a more negative water potential to promote water influx and thus promoting petals cell expansion and flower opening $[20,21]$. We speculated that the principal components of reducing sugars at the bud stage are mainly glucose and fructose due to the fact that sucrose concentration was relatively low when measured alone. As Yamada et al. [9] reported, before flower opening the invertase activity increases markedly because it has to break down sucrose to glucose and fructose to drive petal growth associated with flower opening. In this study, loss of dry weight was clearly shown during senescence of $H$. rosa-sinensis and the reduction in reducing sugars during senescence contributed to the substantial dry matter loss. Contrary to the relative amount of reducing sugars, the sucrose content measured alone significantly increased at the time of petal wilting. This seems to indicate that cells still have adequate reserves

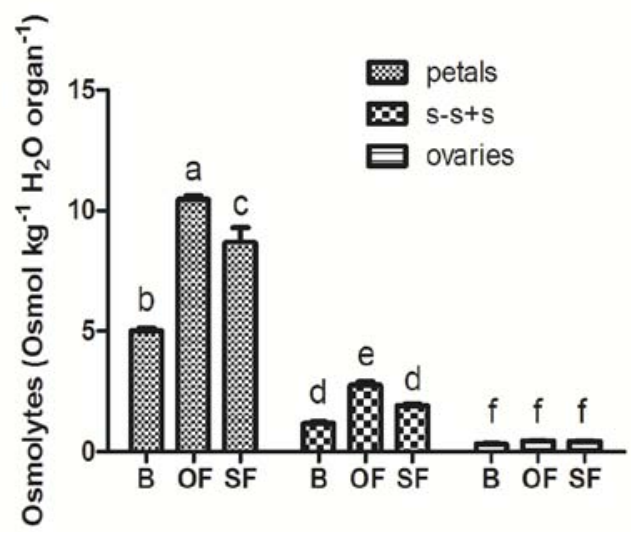

Figure 6. Osmolytes concentration levels in three floral tissue of H. rosa-sinensis among three development stages were measured at bud (B), opened flower (OF) and senescent flower stage (SF). Data were subjected to two way analysis of variance. Different letters above each data point indicate significant differences (Bonferroni's test, $P<0.05)$. Mean values $(n=3) \pm$ standard error $(S E)$. at the time of wilting, which appears contradictory to the positive effect that exogenous sugars exert to enhance the flower longevity $[11,12]$. In fact, the use of carbohydrate and in particular sucrose as additive in the commercial flower preservatives is common. Sugars are used for providing energy for flower opening after storage or transportation, especially in flowers with inflorescences such as gladiolus and snapdragon. In flower stems of cut Protea, glucose or sucrose also were used for preventing leaf blackening [22]. However it is plausible that at some stage during senescence, sugars are formed again due to mobilization, thus the high amount of sucrose at the time of senescence may be a result of mobilization and the sugar accumulation can possibly be viewed as the result of senescence [12]. In Iris, during petal senescence, the expression of the gene encoding sucrose synthase is increased [23], indicating an enhancement in sucrose content. In daylily petals an active sucrose transport into senescent petal was demonstrated [24], determined by phloem loading process. These findings may explain the increase of sucrose in senescent petals of hibiscus.

\subsection{Changes in mineral nutrients accompanying flower development and senescence}

The life of flowers is genetically determined due to their role in sexual reproduction and fertilization, and the maintenance of floral structure has a considerable cost in terms of respiratory energy, nutrients, and water loss $[25,26]$. The flowers are therefore programmed to senesce after pollination or when the stigma is not longer receptive. Before the floral structure is shed, a controlled senescence program allows important nutrients to be salvaged from dying tissues, such as from the petal to the developing ovary or transported to other sink tissues, such as young leaves, before flower death occurs $[27,28]$. In $H$. rosa-sinensis, petals and style-stigma plus stamens the content of $\mathrm{N}, \mathrm{P}, \mathrm{K}$ and $\mathrm{Mg}$ increased during flower opening and subsequently decreased during senescence. The results suggest that these mineral nutrients are likely being remobilized to other sink tissues outside of the flower rather than being transported to the developing ovary, since there were not increases in their levels in the ovaries. The greatest differences in nutrient remobilization between fully open flowers and senescent flowers involved the macronutrient nitrogen. This may indicate that nitrogen is remobilized earlier than $P$ in senescence program, according with the degradation of nucleic acids that is carried out at the latest stage of programmed cell death [29]. Moreover in corolla of transgenic petunia with reduced ethylene sensitivity, the reduction in $\mathrm{P}$ content occurred later than nitrogen [30], and recently Chapin 
and Jones [31] indicated an increase in phosphate transporters steady-state mRNA levels in corolla of senescing petunia that was correlated with a decrease in $\mathrm{P}$ content. In $\mathrm{H}$. rosa-sinensis the decline in $\mathrm{N}$ and $\mathrm{P}$ content appeared to be more closely associated with accumulation of $A B A$ - that peaked at opened flower stage and subsequently declined - rather than with the gradual increase in ethylene production that occurs throughout the flower development [32]. The positive effect of exogenously applied $A B A$ on $N$ remobilization was found during the filling process in grain and $N$ remobilization from vegetative organs to grain was accelerated by the ABA treatment [33]. An additional evidence for a putative role of $A B A$ as a regulatory element in $\mathrm{N}$ remobilization was proposed by Cai et al. [34]. In wheat, the regulation of the high-affinity nitrate transport system (HATS) by exogenous ABA was investigated and the transcript levels of all HATS genes in the roots increased after $A B A$ treatment.

The increase in dry matter in the ovary tissue during the later developmental stages can be related to the changes in the source-sink relationships of the flower tissues during the aging process [35]. The Cawas the most abundant macronutrient in the ovaries of $H$. rosa-sinensis (about $0.2 \mathrm{mg}$ per organ), followed by $\mathrm{P}$ (about $0.15 \mathrm{mg}$ per organ). Free $\mathrm{Ca}$ ions in the ovaries are an important factor during pollen tube growth [36] suggesting a function in supporting the pollen tube growth or in the rejection reactions that can occur during incompatibility $[37,38]$. Moreover $\mathrm{Ca}$ in the form of calcium oxalate crystals is quite abundant in flower organs of many taxa including Malvaceae $[39,40]$, and it functions as cell wall constituent. Also $\mathrm{P}$ is overstocked in the ovary due to its essential role in embryo development $[41,42]$. $P$ is very mobile. and can therefore be transported to sites requiring a great deal of energy such as developing ovary. The mechanism involved in $\mathrm{P}$ transfer is mediated by many enzymes that generally require $\mathrm{Mg}$ as cofactor, and this can also explain the observed relative amount of $\mathrm{Mg}$ in the ovary tissue. Recently it has been shown a transmembrane functional protein receptor kinase, predominantly expressed in ovaries from Solanum chacoense that requires uniquely $\mathrm{Mg}^{2+}$ [43]. Mg bivalent cations in fact serve as catalytically active metal, essential for the autophosphorylation activity of receptor like kinase (RLKs) genes [44]. Regarding the micronutrients, Fe was found the most abundant element in petal tissue (about $14 \mathrm{mg}$ per organ), especially during the transition from bud to open flower stage. Also, the Fe content was considerably high in style-stigma plus stamens (about $5 \mathrm{mg}$ per organ). These results support the hypothesis that during bud opening and flower senescence the increase of LOX activity, a class of non-heme, Fe containing dioxygenase that catalyzes the oxygenation of polyunsaturated fatty acids, can be seen as programmed physiological response. In fact, LOX activity was observed in rapidly growing tissues and was positively correlated with organ elongation rate and petal expansion $[45,46]$. Moreover, the Lox 1 gene isolated in rose was strongly induced in response to petal senescence [47].

The $\mathrm{B}$ content was found to be the highest concentrated micronutrient in the ovaries and in style-stigma plus stamens during flower opening and senescence. This may indicate that plants preferentially accumulate this microelement in ovary and stylestigma plus stamens for their essential role in sexual reproduction. The preferentially accumulation of a mineral nutrient in a particular tissue rather than another, is in keeping with the evidences that the development and the viability of pollen grains and ovules, is adversely affected by deficiencies of micronutrients. In fact, B is a micronutrient that has been found in the reproductive parts of flower, in quite high amounts [48]. In our study the $\mathrm{B}$ concentration of $H$. rosa-sinensis floral tissues was found to be about $6,5.8$ and $1.5 \mu \mathrm{g}$ per organ, in petals, style-stigma plus stamens, and ovaries, respectively. These results support the involvement of $B$ in reproductive processes that has been recently demonstrated by Iwai et al. [49]. They observed that Rhamnogalacturonan-II (RG-II) that acts as the sole receptor for $B$ in plant cells is indispensable for the development of male and female reproductive tissues and the guidance of pollen tubes to the ovary during fertilization. The expression of the NpGUT1 gene involved in the biosynthesis of RG-II is present mainly in the pistil and increases during the development but when it is suppressed the pistil remains immature, resulting in sterility. Similarly, with the trend of NpGUT1 expression, the B content in style-stigma plus stamens increased during the flower development and this raise in B content should be specifically required for crosslinking of cell wall pectin and structural integrity of biomembranes during pollination and fecundation events. In the light of recent studies, the content of a particular mineral nutrient in a given tissue can be related to the requirement of a specific enzyme, activated transcriptionally in a tissue specific manner.

The increase of osmolytes during flower opening has been previously described in Hemerocallis ephemeral flowers [50]. In daylily petals of flowers just prior opening showed an increase of sap and carbohydrate osmolality. These observations are in agreement with the osmolytes concentration observed in petals of hibiscus. Nitrates are also involved in osmoregulation but in carbohydrates 
deficiency conditions [51]. Since all flower organs are rich in sugars, nitrates likely do not play an important role in the osmoregulation, therefore no changes in their concentration were found.

In conclusion, this study reported changes in reducing sugars, sucrose and mineral nutrients content during the development and senescence of $H$. rosasinensis flowers. The spatial and temporal distribution of reducing sugars and sucrose suggests that the high level of reducing sugars prior the onset of flower opening contributes to support petal cells expansion before anthesis, which are closely correlated with osmolytes, while the high amount of sucrose at the time of petal wilting may be seen as a result of senescence. Moreover, the accumulation of mineral nutrients in a tissue specific manner can be considered to be due to the activation of processes directly connected with reproduction and only the major macronutrients appear to be remobilized, as previously reported

\section{References}

[1] Rogers H.J., Programmed cell death in floral organs: How and why do flowers die?, Ann. Bot., 2006, 97, 309-315

[2] Hǿyer L., Critical ethylene exposure for Hibiscus rosa-sinensis is dependent on an interaction between ethylene concentration and duration, Postharvest Biol. Technol., 1996, 9, 87-95

[3] Woodson W.R., Hanchey S.H., Chisholm D.N., Role of ethylene in the senescence of isolated hibiscus petals, Plant Physiol., 1985, 79, 679-683

[4] Trivellini A., Vernieri P., Ferrante A., Serra G., Physiological Characterization of Flower Senescence in Long Life and Ephemeral Ibiscus (Hibiscus rosa-sinensis L.), Acta Hortic., 2007, 755, 457-464

[5] Ho L.C, Nichols R., Translocation of 14C-sucrose in relation to changes in carbohydrate content in rose corollas cut at different stages of development, Ann. Bot., 1977, 41, 227-242

[6] Kaltaler R.E.L., Steponkus P.L., Uptake and metabolism of sucrose in cut roses, J. Am. Soc. Hortic. Sci., 1974, 99, 490-493

[7] Ohyama A., Ito H., Sato T., Nishimura S., Imai T., Hirai M., Suppression of acid invertase activity by antisense rna modifies the sugar composition of tomato fruit, Plant Cell Physiol., 1995, 36, 369-376

[8] Tang G., Luscher M., Sturm A., Antisense repression of vacuolar and cell wall invertase in transgenic carrot alters early plant development and sucrose partitioning, Plant Cell, 1999, 11, 177190 also by Verlinden [13]. Additional research should be carried out to elucidate the nutrient remobilization program occurring during hibiscus flower senescence to establish if the nutrients are remobilized to different sink tissues outside of the flower, such as leaves and new young buds. In this case, a relatively nutritionally cheap process after remobilization of important macronutrients such as $\mathrm{N}, \mathrm{P}$ and $\mathrm{K}$, should occur in other sink tissues. Otherwise hibiscus flowers may be considered as wasteful flowers, since they die within a day without restoring important elements.

\section{Acknowledgements}

This research was funded by the MIUR, PRIN 20072009 of Italy. A PhD scholarship was provided in part by Università degli Studi di Pisa and Sant'Anna School of Advanced Studies.

[9] Yamada K., Itoa M., Oyamaa T., Nakadaa M., Maesakaa M., Yamaki S., Analysis of sucrose metabolism during petal growth of cut roses, Postharvest Biol. Technol., 2007, 43, 174-177

[10] Bieleski R.L., Fructan Hydrolysis Drives Petal Expansion in the Ephemeral Daylily Flower, Plant Physiol., 1993, 103, 213-219

[11] Monteiro J.A., Nell T.A., Barrett J.E., Effects of exogenous sucrose on carbohydrate levels, flower respiration and longevity of potted miniature rose (Rosa hybrida) flowers during postproduction, Postharvest Biol. Technol., 2002, 26, 221-229

[12] van Doorn W.G., Is petal senescence due to sugar starvation?, Plant Physiol., 2004, 134, 35-42

[13] Verlinden S., Changes in mineral nutrient concentrations in Petunia corollas during development and senescence, HortScience, 2003, 38, 71-74

[14] Himelblau E., Amasino R.M., Nutrients mobilized from leaves of Arabidopsis thaliana during leaf senescence, J. Plant Physiol., 2001, 158, 13171323

[15] Page A.L., Miller R.H., Keeney D.R., Chemical and Microbiological Properties, In: Page A.L., (Ed.), Methods of Soil Analysis, $2^{\text {nd }}$ Ed., American Society of Agronomy, USA, 1982

[16] Kacar B., Chemical Analysis of Plant and Soil, University of Ankara, Ankara, 1972

[17] Olsen S.R., Sommers E.L., Phosphorus, In: Page A.L., (Ed.), Methods of Soil Analysis, $2^{\text {nd }}$ Ed., American Society of Agronomy, USA, 1982 
[18] Cataldo D.A., Haroon M., Sehrader L.E., Youngs V.L., Rapid colorimetric determination of nitrate in plant tissue by titration of salicylic acid, Commun. Soil Sci. Plant. Anal., 1975, 6, 71-80

[19] Reid M.S., Wollenweber B., Serek M., Carbon balance and ethylene in the postharvest life of flowering hibiscus, Postharvest Biol. Technol., 2002, 25, 227-233

[20] van Doorn W.G., van Meeteren U., Flower opening and closure: a review, J. Exp. Bot., 2003, 54, 18011812

[21] Yap Y., Loh C., Ong B., Regulation of flower development in Dendrobium crumenatum by changes in carbohydrate contents, water status and cell wall metabolism, Sci. Hortic., 2008, 119, 59-66

[22] Bieleski R.L., Ripperda J., Newman J.P., Reid M.S., Carbohydrate Changes and Leaf Blackening in Cut Flower Stems of Protea eximia, J. Amer. Soc. Hort. Sci., 1992, 117, 124-127

[23] van Doorn W., Balk P.A., van Houwelingen A.M., Hoeberichts F.A, Hall R.D., Vorst O., et al., Gene expression during anthesis and senescence in Iris flowers, Plant Mol. Biol., 2003, 53, 845-863

[24] Bieleski R.L., Onset of phloem export from senescent petals of daylily, Plant Physiol., 1995, 109, 557-565

[25] Jones M.L., Stead A.D., Clark D.G., Petunia Flower Senescence, In: Gerats T., Strommer J., (Eds.), Petunia Evolutionary, Developmental and Physiological Genetics, $2^{\text {nd }}$ Ed., Springer, Germany, 2009

[26] Stead A.D., Pollination-induced flower senescence: a review, Plant Growth Regul., 1992, 11, 13-20

[27] Chapin L., Jones M.L., Nutrient remobilization during pollination-induced corolla senescence in petunia, Acta Hort., 2007, 755, 181-190

[28] Stead A.D., van Doorn W.G., Jones M.L., Wagstaff C., Flower senescence: fundamental and applied aspects, In: Ainsworth C., (Ed.), Flowering and its Manipulation, Annual Plant Reviews, vol. 20, Blackwell Publishing, Oxford, 2006

[29] Jones M.L., Changes in gene expression during senescence, In: Nooden L., (Ed.), Plant Cell Death Process, Elsevier Science, Netherlands, 2004

[30] Jones M.L., Ethylene signaling is required for pollination-accelerated corolla senescence in petunias, Plant Sci., 2008, 175, 190-196

[31] Chapin L.J., Jones M.L., Ethylene regulates phosphorus remobilization and expression of a phosphate transporter (PhPT1) during petunia corolla senescence, J. Exp. Bot., 2009, 60, 21792190
[32] Trivellini A., Ferrante A., Vernieri P., Mensuali-Sodi A., Serra G., Effects of promoters and inhibitors of ethylene and $A B A$ on flower senescence of Hibiscus rosa-sinensis, J. Plant Growth Regul., (in press), DOI: 10.1007/s00344-010-9181-9

[33] Xie Z., Jiang D., Dai T.B., Jing Q., Cao W.X., Effects of exogenous $A B A$ and cytokinin on leaf photosynthesis and grain protein accumulation in wheat ears cultured in vitro, Plant Growth Regul., 2004, 44, 25-32

[34] Cai C., Zhao X.Q., Zhu Y.G., Li B., Tong Y.P., Li Z.S., Regulation of the high-affinity nitrate transport system in wheat roots by exogenous abscisic acid and glutamine, J. Integr. Plant Biol., 2007, 49, 1719-1725

[35] Nichols R., Ho L.C., Effects of ethylene and sucrose on translocation of dry matter and 14c-sucrose in the cut flower of the glasshouse carnation (Dianthus caryophyllus) during senescence, Ann. Bot., 1975, 39, 287-296

[36] Pierson E.S., Miller D.D., Callaham D.A., van Aken J., Hackett G., Hepler P.K., Tip-localized calcium entry fluctuates during pollen tube growth, Dev. Biol., 1996, 174, 160-173

[37] Chudzik B., Sniezko R., Calcium ion presence as a trait of receptivity in tenuinucellar ovules of Galanthus nivalis L., Acta Biol. Cracov. Bot., 2003, 45, 133-141

[38] Kurien A., Radhamany P.M., Differential recognition of self pollen and sterility in Hibiscus rosa-sinensis L. (Malvaceae), Adv. Pollen Spore Res., 2007, 25, 169-176

[39] Tilton V.R., Horner H.T., Calcium oxalate raphide crystals and crystalliferous idioblasts in the carpels of Ornithogalum caudatum, Ann. Bot., 1980, 46, 533-539

[40] Okoli E., McEuen A.R., Calcium-containing crystals in Telfairia hooker (Cucurbitaceae), New Phytol., 1986, 102, 199-207

[41] Harrison C.R., Arditti J., Post-pollination phenomena in orchid flowers, VII. Phosphate movement among floral segments, Am. J. Bot., 1976, 63, 911-918

[42] Goldschmidt E.E., Huberman M., The coordination of organ growth in developing citrus flowers: a possibility for sink type regulation, J. Exp. Bot., 1974, 25, 534-541

[43] Germain H., Houdea J., Gray-Mitsumunea M., Sawasakib T., Endob Y., Rivoala J., et al., Characterization of ScORK28, a transmembrane functional protein receptor kinase predominantly expressed in ovaries from the wild potato species Solanum chacoense, FEBS Lett., 2007, 581, 51375142 
[44] Torii K.U., Leucine-rich repeat receptor kinases in plants: structure, function, and signal transduction pathways, Int. Rev. Cytol., 2004, 234, 1-46

[45] Siedow J.N., Plant Lipoxygenase: structure and function, Annu. Rev. Plant Physiol. Plant Mol. Biol., 1991, 42, 145-188

[46] Kolomiets M.V., Hannapel D.J., Chen H., Tymeson M., Gladon R.J., Lipoxygenase is involved in the control of potato tuber development, Plant Cell, 2001, 13, 613-626

[47] Fukuchi-Mizutani M., Ishiguro K., Nakayama T., Utrunomiya Y., Yoshikazu T., Kusumi T., et al., Molecular and functional characterization of a rose lipoxygenase cDNA related to flower senescence, Plant Sci., 2000, 160, 129-137

[48] O’Neill M.A., Warrenfeltz D., Kates K., Pellerin P., Doco T., Darvill A.G., et al., Rhamnogalacturonan-
II, a Pectic Polysaccharide in the Walls of Growing Plant Cell, Forms a Dimer That Is Covalently Crosslinked by a Borate Ester, J. Biol. Chem., 1996, 271, 22923-22930

[49] Iwai H., Hokura A., Oishi M., Chida H., Ishii T., Sakai S., et al., The gene responsible for borate cross-linking of pectin Rhamnogalacturonan-II is required for plant reproductive tissue development and fertilization, Proc. Natl. Acad. Sci. USA, 2006, 103, 16592-16597

[50] Bieleski R.L., Fructan Hydrolysis Drives Petal Expansion in the Ephemeral Daylily Flower, Plant Physiol., 1993, 103, 213-219

[51] Blom-Zandstra M., Lampe J.E.M., The Role of Nitrate in the Osmoregulation of Lettuce (Lactuca sativa L.) Grown at Different Light Intensities, J. Exp. Bot., 1985, 36, 1043-1052 